\title{
A Critical Role of the Nitric Oxide/cGMP Pathway in Corticostriatal Long-Term Depression
}

\author{
Paolo Calabresi, ${ }^{1}$ Paolo Gubellini, ${ }^{2}$ Diego Centonze, ${ }^{1}$ Giuseppe Sancesario, ${ }^{1}$ Maria Morello, ${ }^{1}$ Mauro Giorgi, ${ }^{3}$ \\ Antonio Pisani, ${ }^{1}$ and Giorgio Bernardi ${ }^{1,4}$ \\ ${ }^{1}$ Clinica Neurologica, Dipartimento di Neuroscienze, Universitá di Roma Tor Vergata, 00133 Rome, Italy, ${ }^{2}$ stituto di \\ Medicina Sperimentale, Consiglio Nazionale delle Ricerche, 00133 Rome, Italy, ${ }^{3}$ Dipartimento di Biologia di Base e \\ Applicata, Università dell'Aquila, 67010 L'Aquila, Italy, and 4IRCCS Ospedale S. Lucia, 00179 Rome, Italy
}

High-frequency stimulation (HFS) of corticostriatal glutamatergic fibers induces long-term depression (LTD) of excitatory synaptic potentials recorded from striatal spiny neurons. This form of LTD can be mimicked by zaprinast, a selective inhibitor of cGMP phosphodiesterases (PDEs). Biochemical analysis shows that most of the striatal cGMP PDE activity is calmodulin-dependent and inhibited by zaprinast. The zaprinast-induced LTD occludes further depression by tetanic stimulation and vice versa. Both forms of synaptic plasticity are blocked by intracellular $1 \mathrm{H}-[1,2,4]$ oxadiazolo[4,3-a]quinoxalin1-one (ODQ), a selective inhibitor of soluble guanylyl cyclase, indicating that an increased cGMP production in the spiny neuron is a key step. Accordingly, intracellular cGMP, activating protein kinase $\mathrm{G}$ (PKG), also induces LTD. Nitric oxide synthase (NOS) inhibitors $N(\mathrm{G})$-nitro-L-arginine methyl ester hydrochloride (L-NAME) and 7-nitroindazole monosodium salt (7-NINA) block LTD induced by either HFS or zaprinast, but not that induced by CGMP. LTD is also induced by the NO donors S-nitroso- $N$-acetylpenicillamine (SNAP) and hydroxylamine. SNAP-induced LTD occludes further depression by HFS or zaprinast, and it is blocked by intracellular ODQ but not by L-NAME. Intracellular application of PKG inhibitors blocks LTD induced by HFS, zaprinast, and SNAP. Electron microscopy immunocytochemistry shows the presence of NOS-positive terminals of striatal interneurons forming synaptic contacts with dendrites of spiny neurons. These findings represent the first demonstration that the NO/cGMP pathway exerts a feedforward control on the corticostriatal synaptic plasticity.

Key words: intracellular recordings; electron microscopy; nitric oxide synthase; calmodulin-dependent phosphodiesterases; striatum; zaprinast
The striatum plays a major role in the regulation of movements, in the storage of motor skills, and in the control of some cognitive activities (Groves, 1983; Graybiel, 1995; Calabresi et al., 1996b, 1997b). GABAergic spiny neurons of the striatum exert this regulatory function by integrating inputs originating from dopaminergic nigrostriatal terminals and glutamatergic corticostriatal axons. These cells project to the output structures of the basal ganglia (Groves, 1983; Graybiel, 1990; Smith and Bolam, 1990). High-frequency stimulation (HFS) of corticostriatal glutamatergic fibers produces long-term depression (LTD) of EPSPs recorded in vitro from spiny neurons (Calabresi et al., 1992b; Lovinger et al., 1993; Walsh, 1993). Thus, it has been hypothesized that corticostriatal synaptic plasticity may represent a cellular substrate for the long-term regulatory control of the striatum in basal ganglia activity (Calabresi et al., 1996b, 1997b).

Spiny cells represent the large majority $(\sim 95 \%)$ of striatal neurons; the remaining neuronal population consists of interneurons. A group of these interneurons contains the neuronal nitric oxide synthase (nNOS) and makes synaptic contacts with spines

\footnotetext{
Received Sept. 28, 1998; revised Jan. 19, 1999; accepted Jan. 21, 1999.

This study was supported by a Ministero dell' Università e della Ricerca Scientifica e Technologica grant and a BIOMED grant (BMH4-97-2215) to P.C., by a Consiglio Nazionale delle Ricerche (CNR) grant (96000) to G.S., and by a MURST-CNR (legge 95/95) grant to G.B. We thank M. Tolu and A. Modica for the technical assistance and Dr. E. Fedele for reading this manuscript.

Correspondence should be addressed to Dr. Paolo Gubellini, Clinica Neurologica, Dipartimento di Neuroscienze, Universitá di Roma Tor Vergata, Via di Tor Vergata, 00133 Roma, Italy.

Copyright (C) 1999 Society for Neuroscience $\quad 0270-6474 / 99 / 192489-11 \$ 05.00 / 0$
}

of putative medium spiny neurons (Vincent and Kimura, 1992; Kawaguchi et al., 1995; Morello et al., 1997). These nNOSpositive cells receive excitatory inputs from the cortex and express mRNA encoding for ionotropic glutamate receptors that appear to be coupled to nitric oxide (NO) production (East et al., 1996). NO elevates intracellular cGMP levels through activation of soluble guanylyl cyclase (sGC); a primary action of increased cGMP concentration is the stimulation of cGMP-dependent protein kinase (PKG) (Wang and Robinson, 1997). Immunohistochemical studies have revealed the presence of high levels of sGC in spiny neurons (Ariano et al., 1982; Ariano, 1983). Striatal spiny neurons also express high levels of calmodulin (CaM)-dependent phosphodiesterases (PDEs), enzymes that metabolize cGMP with high efficiency (Polli and Kincaid, 1994; Yan et al., 1994). In hippocampus and cerebellum, the discovery of NO as an intercellular messenger stimulated new concepts about the formation of synaptic plasticity. However, although initial reports found that $\mathrm{NO}$ is required as a retrograde messenger for hippocampal longterm potentiation (LTP), other studies failed to confirm these results (Schuman and Madison, 1991; Bon et al., 1992; Gribkoff and Lum-Ragan, 1992; Haley et al., 1993; Kato and Zorumski, 1993; Williams et al., 1993; Boulton et al., 1995; Malen and Chapman, 1997). Deletion of the gene that encodes NOS in mice showed that both nNOS and endothelial NOS (eNOS) are expressed in the brain, and deletion of both isoforms reduced the inducibility of hippocampal LTP (Son et al., 1996). Also, the involvement of NO in cerebellar LTD has been considered controversial. In cerebellar slices, extracellular application of hemo- 
globin (a scavenger of NO) and NOS inhibitors blocked LTD (Crépel and Jaillard, 1990; Shibuki and Okada, 1991; Daniel et al., 1993), whereas bath application of NO donors (Shibuki and Okada, 1991; Daniel et al., 1993) or release of caged NO into Purkinje cells during depolarization of the neurons (Lev-Ram et al., 1995, 1997) caused a depression of synaptic transmission that occludes LTD. Another study failed to detect depressant effects of a NO donor (Glaum et al., 1992). Moreover, in a model of postsynaptic LTD in cultured Purkinje cells, hemoglobin or NOS inhibition did not prevent the depression in glutamate sensitivity nor could it be mimicked by an exogenously applied NO donor (Linden and Connor, 1992).

To investigate whether the NO/cGMP pathway is active during the LTD formation in striatum, we have studied the effects of a set of drugs able to interfere with four different components of the NO/cGMP pathway: (1) cGMP degradation, (2) cGMP production, (3) NO levels, and (4) PKG activity. We have also studied by immunocytochemistry the ultrastructural relationships between NOS-positive terminals, dendritic spines, and contiguous NOSnegative terminals within the striatum.

\section{MATERIALS AND METHODS}

Electrophysiological experiments. Wistar rats (150-250 gm) were used. The preparation and maintenance of coronal slices have been described previously (Calabresi et al., 1990, 1991, 1992a,b, 1994). Briefly, corticostriatal coronal slices $(200-300 \mu \mathrm{m})$ were prepared from tissue blocks of the brain with the use of a vibratome. A single slice was transferred to a recording chamber and submerged in a continuously flowing Krebs solution $\left(35^{\circ} \mathrm{C}, 2-3 \mathrm{ml} / \mathrm{min}\right)$ gassed with $95 \% \mathrm{O}_{2} / 5 \% \mathrm{CO}_{2}$. Complete replacement of the medium in the chamber took $\sim 90 \mathrm{sec}$ as detected by the speed of diffusion of a colored solution. The control solution was composed of the following (in mM): $126 \mathrm{NaCl}, 2.5 \mathrm{KCl}, 1.2 \mathrm{MgCl}_{2}, 1.2$ $\mathrm{NaH}_{2} \mathrm{PO}_{4}, 2.4 \mathrm{CaCl}_{2}, 11$ glucose, and $25 \mathrm{NaHCO}_{3}$.

The intracellular recording electrodes were filled with $2 \mathrm{M} \mathrm{KCl} \mathrm{(30-60}$ $\mathrm{M} \Omega$ ). An AxoClamp 2B amplifier was used for recordings either in current-clamp or voltage-clamp mode. In single microelectrode voltageclamp mode, the switching frequency was $3 \mathrm{kHz}$. The headstage signal was continuously monitored on a separate oscilloscope. Current-voltage relationships and changes in membrane conductance were detected by the application of voltage steps in both positive and negative directions (1-3 sec duration, 5-15 mV amplitude). Traces were displayed on an oscilloscope and stored on a digital system. For synaptic stimulation, bipolar electrodes were used. The stimulating electrode was located either in the cortical areas close to the recording electrode $(0.5-3 \mathrm{~mm})$ or in the white matter between the cortex and the striatum. As conditioning tetanus, we used three trains ( $3 \mathrm{sec}$ duration, $100 \mathrm{~Hz}$ frequency, at $20 \mathrm{sec}$ intervals). During tetanic stimulation, the intensity was increased to suprathreshold levels. Quantitative data on EPSP modifications induced by tetanic stimulation are expressed as a percentage of the controls, the latter representing the mean of responses recorded during a stable period $(15-20 \mathrm{~min})$ before the tetanus. Values given in the text and in the figures are mean \pm SEM of changes in the respective cell populations. Student's $t$ test (for paired and unpaired observations) was used to compare the means. Control experiments on synaptic plasticity were interleaved with the pharmacological experiments in which the various compounds were used.

Drugs were applied by dissolving them to the desired final concentration in the saline and by switching the perfusion from control saline to drug-containing saline. Adenosine, BAPTA, 8-cyclopentil-1,3dipropylxanthine (DPCPX), 8-methoxymethyl-IBMX (8-MM-IBMX), D-2-amino-5-phosphonovalerate (D-APV), and guanosine 3',5'-cyclic monophosphorothioate, Rp-isomer, sodium salt (Rp-cGMPS) were from Sigma-Aldrich. 6-Cyano-7-nitroquinoxaline-2,3-dione (CNQX), 1H[1,2,4] oxadiazolo[4,3-a]quinoxalin-1-one (ODQ), N(G)-nitro-L-arginine methyl ester hydrochloride (L-NAME), 7-nitroindazole monosodium salt (7-NINA), and $S$-nitroso- $N$-acetylpenicillamine (SNAP) were from Tocris Cookson. cGMP and guanosine $3^{\prime}, 5^{\prime}$-cyclic monophosphorothioate, 8-bromo, Rp-isomer, sodium salt (Rp-8-Br-cGMPS) were from Calbiochem (La Jolla, CA). Hydroxylamine was from Merck (Darmstadt, Germany). Zaprinast (M\&B 22948, 2-o-propoxyphenyl-8azapurin-6-one) was a generous gift of Rhône-Poulenc Rorer (Dagen- ham, UK). KS-505a was a kind gift of Pharmaceutical Research Laboratories Kyowa Hakko Kogyo Co. (Tokyo, Japan). In some experiments, biocytin (Sigma-Aldrich) was used in the intracellular electrode to stain the neurons. In these cases, biocytin at a concentration of $2-4 \%$ was added to a $0.5 \mathrm{M} \mathrm{KCl}$ pipette solution. Slices containing neurons stained with biocytin were fixed in paraformaldehyde (in $0.1 \mathrm{M}$ phosphate buffer at $\mathrm{pH}$ 7.4) overnight and processed according to published protocols (Horikawa and Armstrong, 1988). In several cases, sections were further processed to produce permanent staining of biocytin-loaded cells.

Biochemical experiments. Striatal slices were homogenized in $20 \mathrm{~mm}$ Tris-HCl, pH 7.2, 1 mm EGTA, 5 mM $\mathrm{MgCl}_{2}, 5 \mathrm{~mm} \beta$-mercaptoethanol, $10 \mu \mathrm{g} / \mathrm{ml}$ leupeptin, $5 \mu \mathrm{g} / \mathrm{ml}$ pepstatin, $5 \mu \mathrm{g} / \mathrm{ml}$ bestatin, and $0.2 \mathrm{~mm}$ PMSF and homogenized at $4^{\circ} \mathrm{C}$ in a glass-Teflon homogenizer with 20 strokes. The tissue extract was centrifuged for $30 \mathrm{~min}$ at $20,000 \times g$; the pellet was resuspended in homogenization buffer and centrifuged for 30 $\min$ at $20,000 \times g$. The first and second supernatants were then pooled. This supernatant was referred as "crude extract." The enzyme extract (1 $\mathrm{mg}$ of protein) was diluted 1:2 with $50 \mathrm{~mm}$ sodium acetate, $\mathrm{pH} 6.5$, containing $1 \mathrm{~mm}$ EGTA, $5 \mathrm{mM} \beta$-mercaptoethanol, and $0.2 \mathrm{mM}$ PMSF (buffer A) and loaded onto a $1 \mathrm{ml}$ DEAE-sephadex column (Sigma, St. Louis, MO) pre-equilibrated with the same buffer. After wash with six bed volumes of buffer A, cGMP PDE activity was eluted with 5 bed volumes of $600 \mathrm{~mm}$ sodium acetate solution in buffer A. This CaMdepleted sample was supplemented with protease inhibitors, $0.5 \mathrm{mg} / \mathrm{ml}$ $\mathrm{BSA}$, and $2 \mathrm{mM} \mathrm{CaCl}{ }_{2}$ and loaded onto $0.5 \mathrm{ml}$ of CaM-Sepharose $4 \mathrm{~B}$ column (Pharmacia, Uppsala, Sweden), which was previously equilibrated with buffer B ( $25 \mathrm{~mm}$ HEPES, $\mathrm{pH} 7.2,5 \mathrm{~mm} \mathrm{MgCl}_{2}, 1$ mM EGTA, $2 \mathrm{mM} \mathrm{CaCl}_{2}, 0.5 \mathrm{mg} / \mathrm{ml}$ BSA, $250 \mathrm{~mm} \mathrm{NaCl}$ ). The column was washed with buffer $\mathrm{B}$, and $\mathrm{Ca}^{2+}-\mathrm{CaM}$-dependent PDE activity was eluted with 5 bed volumes of buffer B supplemented of $4 \mathrm{~mm}$ EGTA. The CaMSepharose eluate and the part of the sample that did not bind the column were further assayed for cGMP PDE activity. PDE activity was determined by the two-step method, as described (Thompson and Appleman, 1971), in a final volume of $0.3 \mathrm{ml}$ of assay buffer (60 mM HEPES, $\mathrm{pH} 7.2$, $0.1 \mathrm{~mm}$ EDTA, $0.1 \mathrm{~mm}$ EGTA, $5 \mathrm{~mm} \mathrm{MgCl} 2,0.5 \mathrm{mg} / \mathrm{ml} \mathrm{BSA}, 30 \mu \mathrm{g} / \mathrm{ml}$ soybean trypsin inhibitor) using $1 \mu \mathrm{M}\left[{ }^{3} \mathrm{H}\right]$ cGMP (Amersham, Arlington Heights, IL) in the presence of $0.4 \mathrm{~mm} \mathrm{CaCl}_{2}$ and $3 \mu \mathrm{g} / \mathrm{ml}$ calmodulin.

Morphological experiments. Wistar rats (150-250 gm) were deeply anesthetized (chloral hydrate, $400 \mathrm{mg} / \mathrm{kg}$, i.p.) and intracardially perfused through the ascending aorta with $200 \mathrm{ml}$ of saline containing heparin sodium salt $(0.1 \mathrm{gm} / 100 \mathrm{ml}$, Sigma), followed by $200 \mathrm{ml}$ of a fixative solution containing $4 \%$ paraformaldehyde, $0.1 \%$ glutaraldehyde, and $15 \%$ saturated picric acid in $0.1 \mathrm{M}$ sodium phosphate buffer (PB). After perfusion the brains were post-fixed overnight in a solution of $\mathrm{PB}$ containing $4 \%$ paraformaldehyde. Frontal sections (40 $\mu \mathrm{m}$ thick) were cut using a vibratome through the rostral striatum. Sections were then processed for electron microscopy immunohistochemistry using a specific antibody for neuronal NOS, as described previously (Morello et al., 1997). Briefly, the sections were incubated overnight in an affinitypurified rabbit anti-brain NOS (Transduction Laboratories, Lexington, KY) diluted 1:500. The sections were then incubated for $1 \mathrm{hr}$ with donkey anti-rabbit IgG secondary antibody (Jackson ImmunoResearch, West Grove, PA) diluted 1:50 and then incubated for $2 \mathrm{hr}$ in peroxidaseantiperoxidase complex (PAP) (Sternberger Monoclonals) diluted 1:100 in PBS. After incubation in PAP, the tissue was then washed three times in $0.1 \mathrm{M} \mathrm{PB}$, and the localization of the immunologically bound peroxidase was visualized using 3,3'-diaminobenzidine tetrahydrochloride (DAB) as the chromogen for a peroxidase immunohistochemical procedure.

All sections were post-fixed in osmium tetroxide, stained en bloc with uranyl acetate, dehydrated in graded ethanol, and flat-embedded in Spurr (Spurr's Kit, Electron Microscopy Science). Under a stereomicroscope, several small specimens were cut from dorsal-lateral striatum, and glued to prepolymerized Spurr blocks. Ultrathin $70 \mathrm{~nm}$ sections were cut from the surface of the tissue blocks, using an ultramicrotome. They were lightly stained with lead citrate and examined in the electron microscope operating at $80 \mathrm{KV}$.

NOS-positive perikarya, dendrites, and terminals were identified by the DAB reaction product within them, as reported previously (Morello et al., 1997). Every apparent NOS-positive synaptic terminal (identified by the presence of round vesicles) that was encountered was photographed until 200 of them were counted. The NOS-positive terminals were considered as either being simply contiguous to or making special- 
ized synaptic contacts with surrounding cells or both. The pattern of ultrastructural relationships of these NOS-positive terminals with nearby unlabeled structures was characterized and quantified on the printed photographs.

\section{RESULTS}

\section{Morphological and electrophysiological properties of} the recorded neurons

Intracellular recordings were obtained from striatal spiny neurons by using a corticostriatal brain slice preparation (Calabresi et al., 1990, 1991). The electrophysiological and morphological characteristics of these neurons have been reported previously (Kitai et al., 1976; Herrling, 1985; Cherubini et al., 1988; Calabresi et al., 1991, 1992a; Jiang and North, 1991). They have a small soma (10-18 $\mu \mathrm{m})$ and an extensive dendritic tree, densely studded with spines. These cells had high resting membrane potential $(-84 \pm$ $5 \mathrm{mV})$, relatively low apparent input resistance $(38 \pm 8 \mathrm{M} \Omega$ ) when measured at the resting potentials from the amplitude of small $(<10 \mathrm{mV})$ hyperpolarizing electrotonic potentials, and action potentials of short duration $(1.1 \pm 0.3 \mathrm{msec})$ and high amplitude $(102 \pm 4 \mathrm{mV})$. These cells were silent at rest and showed membrane rectification and tonic firing activity during depolarizing current pulses. Cells studied with voltage-clamp showed prominent inward rectification in the steady-state current-voltage relation. When hyperpolarizing command steps evoked the currents, there was no detectable time-dependent component. In the presence of a physiological concentration of magnesium (1.2 mM), synaptic stimulation of corticostriatal afferents induced EPSPs that were blocked by CNQX, an antagonist of AMPA-like glutamate receptors, but not by APV, an NMDAglutamate receptor antagonist (Herrling, 1985; Cherubini et al., 1988; Calabresi et al., 1991, 1992a; Jiang and North, 1991).

\section{Characteristics of tetanus-induced LTD}

As reported previously (Calabresi et al., 1992a, 1994), in most of the recorded neurons (16 of 20), a rapid (2-5 min) and persistent $(>1 \mathrm{hr} ; p<0.001)$ reduction of the EPSP amplitude was observed after the conditioning HFS (see Materials and Methods for details). In some cells $(n=4)$, a transient $(1-5 \mathrm{~min})$ potentiation preceded the LTD induction. Figure $1 A$, top graph, shows the time course of the tetanus-induced LTD in the absence of any pharmacological manipulation. It has recently been reported that in slices obtained from young rats LTD induced by HFS was associated with an increased paired-pulse facilitation, suggesting that during the early developmental phases, corticostriatal LTD requires the involvement of presynaptic mechanisms (Choi and Lovinger, 1997). In fact, any change in paired-pulse facilitation has been considered to be an index of modified presynaptic release (Calabresi et al., 1997a; Kleschevnikov et al., 1997). To investigate the possible involvement of presynaptic mechanisms in LTD expressed in adult slices, we measured the EPSP2/EPSP1 ratio before and after the induction of LTD. The delay between the two stimuli was 50-60 msec. Surprisingly, in adult slices the HFS-induced depression of synaptic potentials was not associated with an altered EPSP2/EPSP1 ratio, suggesting that at least under our experimental conditions, presynaptic factors do not play a prominent role in the maintenance of this form of synaptic plasticity (Fig. 1A, middle traces and bottom graph).

\section{Biochemical effects of zaprinast on striatal PDEs}

To test whether the electrophysiological effects of zaprinast were dependent on the inhibitory action of the cGMP breakdown, we analyzed the zaprinast-induced inhibition of the cGMP PDE
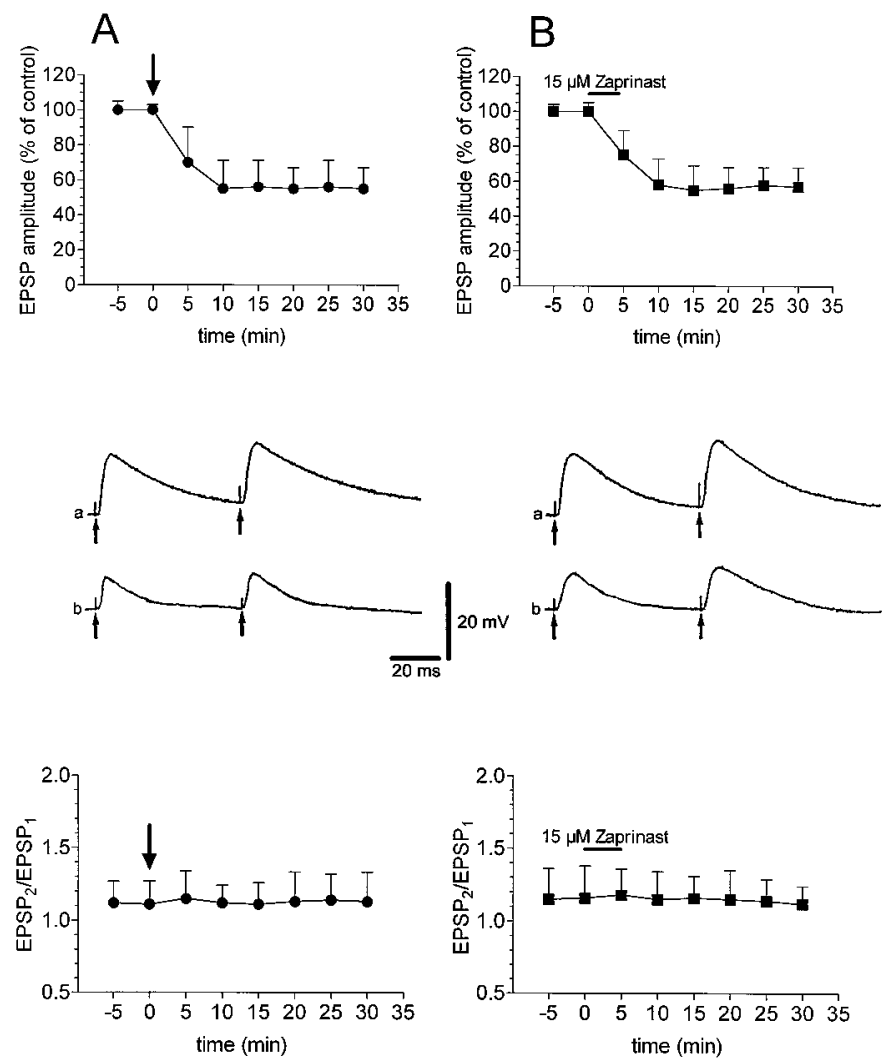

Figure 1. LTD of corticostriatal transmission can be induced either by tetanic stimulation or by zaprinast application. $A$, The top graph shows the time course of the LTD induced by the tetanic stimulation of corticostriatal afferents (large arrow). Traces shown in the middle of the figure represent two EPSPs evoked by a paired-pulse stimulation (small arrows, $60 \mathrm{msec}$ interval) in a striatal spiny neuron under control condition $(a)$ and $30 \mathrm{~min}$ after the induction of LTD $(b)$ (resting membrane potential $=-85 \mathrm{mV}$ ). The bottom graph represents the EPSP2/EPSP1 ratio measured before and after the induction of LTD. $B$, The top graph shows the time course of the LTD induced by the application of $15 \mu \mathrm{M}$ zaprinast (black bar). Traces shown in the middle of the figure represent two EPSPs evoked by a paired-pulse stimulation (small arrows, $60 \mathrm{msec}$ interval) in another striatal spiny neuron under control condition $(a)$ and 30 min after the induction of LTD $(b)$ (resting membrane potential $=-86 \mathrm{mV}$ ). The bottom graph represents the EPSP2/EPSP1 ratio measured before and after the induction of LTD. Control experiments reported in the top graphs are the same as those shown in Figures 5, 6, and 8.

activity by measurements on crude extracts of striatal slices (see Materials and Methods) (Fig. 2C). The $\mathrm{EC}_{50}$ obtained from these experiments was $22 \mu \mathrm{M}$. Although central neurons express various families of PDEs (Beavo, 1995), striatal spiny neurons are highly enriched with CaM-dependent PDE (PDE1) (Polli and Kincaid, 1994; Yan et al., 1994). However, zaprinast is also a potent inhibitor of PDE5, which is mainly expressed in the cerebellum (Beavo, 1995). To analyze the possible contribution of these different PDEs to the effects of zaprinast, striatal crude extracts were first depleted of endogenous $\mathrm{CaM}$ and then loaded in the CaM-Sepharose column, which selectively binds CaMdependent PDEs (see Materials and Methods). Only $2.3 \%$ of cGMP PDE activity did not bind the column, whereas $97.7 \%$ remained in the column and was eluted in EGTA-containing buffer, suggesting that most of the cGMP PDE activity of the striatum is $\mathrm{CaM}$ dependent. Accordingly, the $\mathrm{EC}_{50}$ of the zaprinast-induced inhibition of the cGMP PDE activity obtained 
Figure 2. Physiological, pharmacological, and biochemical characteristics of the zaprinast effect. $A$, The LTD induced by tetanic stimulation (arrow) occludes further depression by zaprinast application (black bar; top graph) and vice versa (bottom graph). $B$, The graph shows that the control EPSP recorded from a striatal spiny neuron is reduced by $100 \mu \mathrm{M}$ adenosine; incubation of the slice in the presence of 300 nM DPCPX increases EPSP amplitude and antagonizes the inhibitory action of the same dose of adenosine but not the induction of LTD by $15 \mu \mathrm{M}$ zaprinast application. $C$, Shown is the dose-response curve for the effect of zaprinast on the striatal cGMP PDE activity. The activity was measured in the presence of $0.4 \mathrm{mM} \mathrm{Ca}^{2+}$ and $3 \mu \mathrm{g} / \mathrm{ml}$ of calmodulin using $1 \mu \mathrm{M}$ cGMP as substrate. See Results for further details.
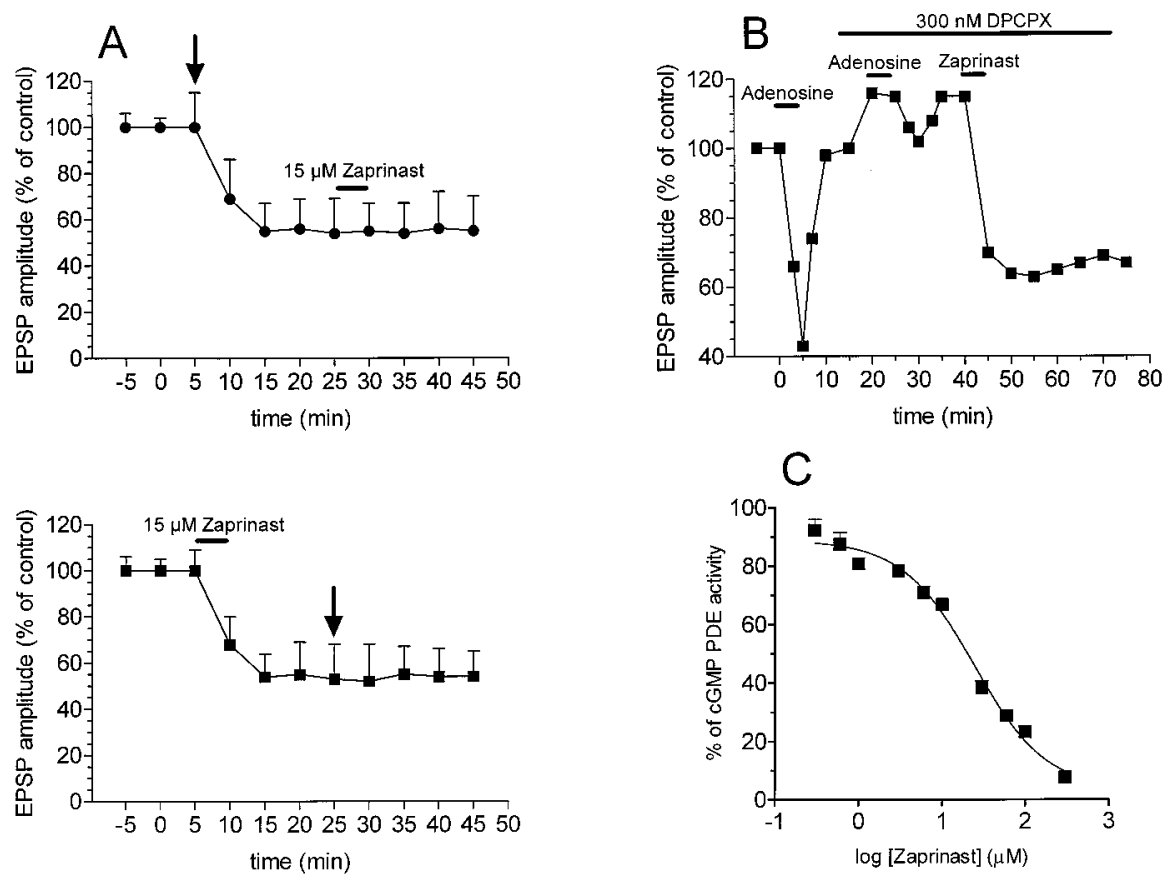

from striatal extracts eluted from the CaM-Sepharose column was the same as that measured from crude extracts.

\section{Action of intracellular BAPTA}

A rise in the $\mathrm{Ca}^{2+}$ intracellular concentration is necessary for long-term changes of synaptic transmission in different neuronal types (Bliss and Collingridge, 1993). Intracellular injection of $\mathrm{Ca}^{2+}$ chelators also blocks LTD induced by HFS of corticostriatal afferents (Calabresi et al., 1994). To examine the role of intracellular $\mathrm{Ca}^{2+}$ in the zaprinast-induced LTD, we injected striatal neurons $(n=7)$ with $200 \mathrm{~mm}$ BAPTA for 20-30 min before applying $15 \mu \mathrm{M}$ zaprinast. The long-term depression of intracellularly recorded EPSP was suppressed under these experimental conditions. Moreover, to ensure that under these conditions zaprinast would still be able to generate LTD, we simultaneously recorded the extracellular field potential from the neighboring neurons $(n=7)$. In contrast to the lack of effect observed for the intracellularly recorded EPSP, the amplitude of the extracellularly recorded field potential showed a long-term depression in response to zaprinast application (data not shown).

\section{Occlusion experiments and adenosine receptor antagonism}

To determine whether the zaprinast-induced LTD occurred through processes common to the HFS-induced one, occlusion experiments were performed. Figure $2 A$ (top graph) illustrates that after tetanic LTD, further depression was not observed after bath application of zaprinast $(n=4)$. Similarly, after induction of LTD by the zaprinast application, additional LTD was not produced by HFS ( $n=4)$ (Fig. $2 A$, bottom graph).

In the hippocampus, the zaprinast-induced depression of field excitatory potentials, elicited by stimulation of the Schaffer collateral-commissural pathway, is mediated through adenosine A1 receptors (Broome et al., 1994). The specific adenosine A1 receptor antagonist DPCPX was used to determine whether the effect of zaprinast on corticostriatal transmission was mediated through this receptor subtype. As shown previously (Calabresi et al., 1997a), DPCPX (300 nM) induced a slight but significant
$(+14 \pm 5 \%, n=8 ; p<0.001)$ increase in the EPSP amplitude, indicating a basal level of the adenosine activity (Fig. 2B). Moreover, this antagonist significantly reduced the inhibitory action of adenosine $(100 \mu \mathrm{M})$ on corticostriatal EPSP. In the presence of DPCPX, zaprinast-induced LTD was indistinguishable from that observed in untreated slices, suggesting that $\mathrm{A} 1$ receptors are not involved in this form of synaptic plasticity $(n=4)$ (Fig. $2 B)$. This idea was further supported by the finding that the adenosineinduced depression of EPSP amplitude, unlike LTD, was associated with increased paired-pulse facilitation (data not shown).

\section{Intracellular application of zaprinast and cGMP}

The experiments showing that bath application of zaprinast induces LTD suggest that a postsynaptic cGMP elevation is sufficient to induce this form of synaptic plasticity. To confirm a postsynaptic site for this electrophysiological effect, we used two experimental approaches. In a first set of experiments, we intracellularly applied $200 \mu \mathrm{M}$ zaprinast through the recording microelectrode. Figure $3 A$ shows that this procedure caused a progressive depression of the EPSP amplitude that reached a plateau after 20-25 min of recording $(n=8)$. Moreover, further depression either by HFS ( $n=4)$ (Fig. $3 A$, top graph) or by bath application of $15 \mu \mathrm{M}$ zaprinast $(n=4)$ (Fig. $3 A$, bottom graph) was occluded under these experimental conditions. In a second set of experiments, we applied $5 \mu \mathrm{M}$ cGMP, the PKG activator, through the recording micropipette. As shown in Figure $3 B$, this drug also produced a progressive depression of the EPSP amplitude $(n=$ 6), with a time course similar to the one observed for intracellular zaprinast. Also, this LTD occluded further depression by HFS $(n=3)$ (Fig. 3B, top graph) or bath-applied $15 \mu \mathrm{M}$ zaprinast $(n=$ 3) (Fig. 3B, bottom graph), suggesting that these electrophysiological events require the same transduction mechanism. Neither intracellular zaprinast $(n=8)$ nor cGMP $(n=6)$ altered the resting membrane potential of the recorded neurons, input resistance, and current-evoked firing discharge (data not shown). To show that the depression of the EPSP during the intracellular application of zaprinast or cGMP was caused by a pharmacolog- 
A
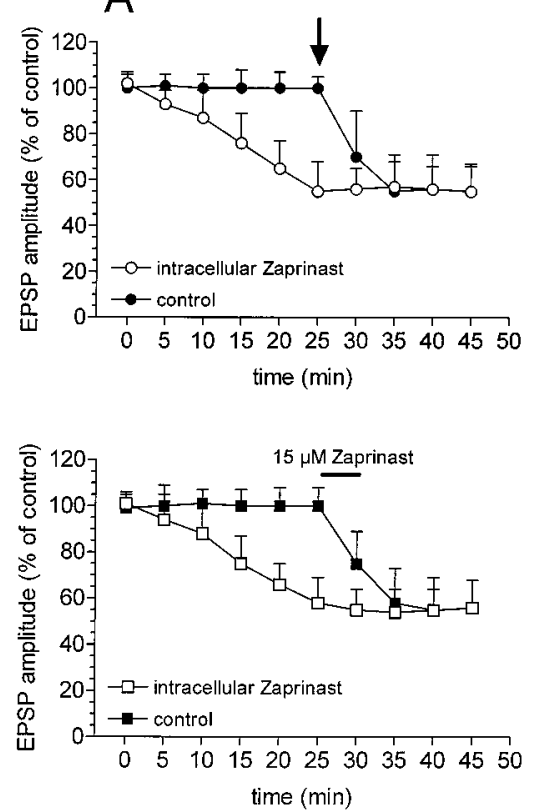

B
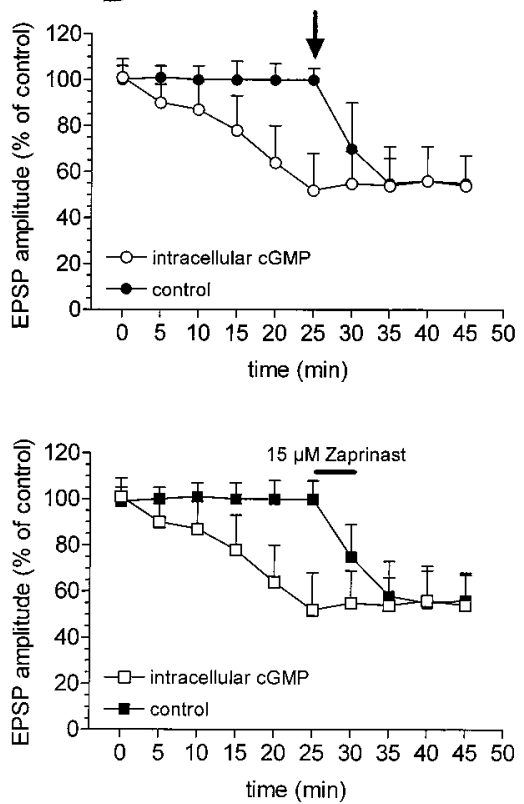

Figure 3. Intracellular injection of zaprinast or cGMP induces postsynaptic LTD. $A$, Intracellular application of $100 \mu \mathrm{M}$ zaprinast via the recording microelectrode induces a progressive and persistent decrease of EPSP amplitude that reaches a plateau after 25-30 min and occludes any further depression by HFS (top graph) and bath-applied $15 \mu \mathrm{M}$ zaprinast (bottom graph). B, Intracellular application of $5 \mu \mathrm{M} \mathrm{cGMP}$ via the recording microelectrode induces a progressive and persistent decrease of EPSP amplitude that reaches a plateau after 25-30 min and occludes any further depression by HFS (top graph) and bath-applied $15 \mu \mathrm{M}$ zaprinast (bottom graph). ical effect rather than by a rundown of the synaptic potential, we performed control experiments in which EPSPs were stable during the whole period of recording. In these control experiments, both HFS and bath application of $15 \mu \mathrm{M}$ zaprinast caused a significant LTD (Fig. 3, filled symbols).

\section{Induction of LTD by zaprinast and other PDE inhibitors}

Studies on cerebellar slices have shown that mechanisms controlling the formation and degradation of cGMP may have a key role in the modulation of LTD recorded from Purkinje neurons (Hartell, 1996). Thus, we have investigated whether zaprinast, a selective inhibitor of cGMP PDEs (Beavo and Reifsnyder, 1990), might promote LTD at the corticostriatal synapses. The basal EPSP amplitude was reduced in all recorded neurons $(n=22)$ after the application of $15 \mu \mathrm{M}$ zaprinast for periods lasting 5-7 min (Fig. $1 B$, top graph). This effect was long lasting $(>1 \mathrm{hr})$; indeed, after the wash of this PDE inhibitor the EPSP amplitude did not recover. Applications of zaprinast $>5-7 \mathrm{~min}$ did not further decrease the EPSP amplitude, indicating that the effect of this drug reached the steady state within this period (data not shown). Moreover, the effect of this drug on the EPSP amplitude was not coupled with changes in membrane potential $(n=22 ; p>$ $0.05)$, input resistance $(n=18 ; p>0.05)$, and action potential discharge evoked by depolarizing pulses $(n=10 ; p>0.05)$. Interestingly, as observed for LTD caused by HFS, this "pharmacological" LTD was not associated with changes in pairedpulse facilitation (Fig. $1 B$, middle traces and bottom graph). The reduction of the EPSP amplitude induced by zaprinast was dosedependent $(1 \mu \mathrm{M}=-2 \pm 5 \%, n=5 ; 5 \mu \mathrm{M}=-16 \pm 8 \%, n=7$; $15 \mu \mathrm{M}=-41 \pm 10 \%, n=18 ; 50 \mu \mathrm{M}=-43 \pm 17 \%, n=5)$, showing an $\mathrm{EC}_{50}$ of $9 \mu \mathrm{M}$. We also tested the electrophysiological effects of 8-MM-IBMX (Beavo, 1995; Yu et al., 1997) and KS505a (Beavo, 1995; Ichimura et al., 1996), two PDE inhibitors that have been reported to act at type I PDE more selectively than zaprinast. Bath application of $100 \mu \mathrm{M}$ 8-MM-IBMX for $5 \mathrm{~min}$ induced a transient (7-14 min) potentiation of the EPSP amplitude $(+35 \pm 5 \% ; n=4 ; p<0.001)$ followed by a long-lasting $(>30 \mathrm{~min})$ depression of this potential $(-40 \pm 6 \% ; n=4 ; p<0.001)$ (Fig. 4).

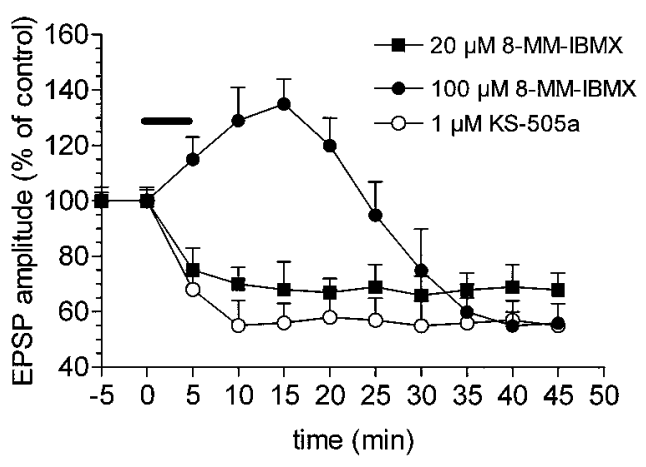

Figure 4. Effect of 8-MM-IBMX and KS-505a on the corticostriatal EPSP amplitude. Bath application of $100 \mu \mathrm{M} 8$-MM-IBMX (๑) produces a transient increase of the EPSP amplitude, followed by an LTD similar to the one observed with zaprinast. A lower dose $(20 \mu \mathrm{M}, \mathbf{\square})$ of 8-MMIBMX induced only a long-lasting depression. Bath application of $1 \mu \mathrm{M}$ KS-505a (O) rapidly decreases the EPSP amplitude, inducing an LTD similar to the one observed with zaprinast.

A lower concentration of 8-MM-IBMX (20 $\mu \mathrm{M} ; n=5)$ induced a long-lasting inhibition of the EPSP amplitude in the absence of the transient potentiation (Fig. 4). Also KS-505a (1 $\mu \mathrm{M})$ induced a rapid ( $<5 \mathrm{~min})$ and long-lasting $(>30 \mathrm{~min})$ depression of EPSP amplitude $(-42 \pm 5 \% ; n=4 ; p<0.001)$ (Fig. 4). As well as zaprinast, neither 8-MM-IBMX nor KS-505a altered membrane potential and input resistance of the recorded cells.

\section{Effect of ODQ}

Immunocytochemical studies indicate a strong expression of sGC in striatal spiny neurons (Ariano et al., 1982; Ariano, 1983), suggesting that the cGMP produced by this enzyme might play a key role in the formation of corticostriatal LTD. To examine this issue, we used ODQ, a potent and selective inhibitor of this enzyme (Garthwaite et al., 1995; Boxall and Garthwaite, 1996). In five experiments, ODQ was intracellularly injected through the recording electrode; after 15-20 min of recording with $100 \mu \mathrm{M}$ ODQ-filled electrodes, the HFS was unable to induce LTD $(n=$ 
Figure 5. ODQ prevents both the tetanus- and the zaprinast-induced LTD. $A$ (top graph), LTD induced by the tetanic stimulation under control condition is prevented in experiments in which the slices were incubated in the presence of 10 $\mu \mathrm{M}$ ODQ. Bottom graph, Zaprinast-induced LTD is prevented by $10 \mu \mathrm{M}$ ODQ. $B$, The intracellular application of $100 \mu \mathrm{M}$ ODQ via the recording microelectrode blocks the formation of both the tetanus-induced (top graph) and zaprinast-induced LTD (bottom graph).

Figure 6. Corticostriatal LTD is inhibited by either L-NAME or 7-NINA. $A$, Bath application of $50 \mu \mathrm{M}$ L-NAME blocks both tetanus-induced (top graph) and zaprinast-induced LTD (bottom graph). $B$, These forms of synaptic plasticity are also blocked by $10 \mu \mathrm{M}$ 7-NINA.
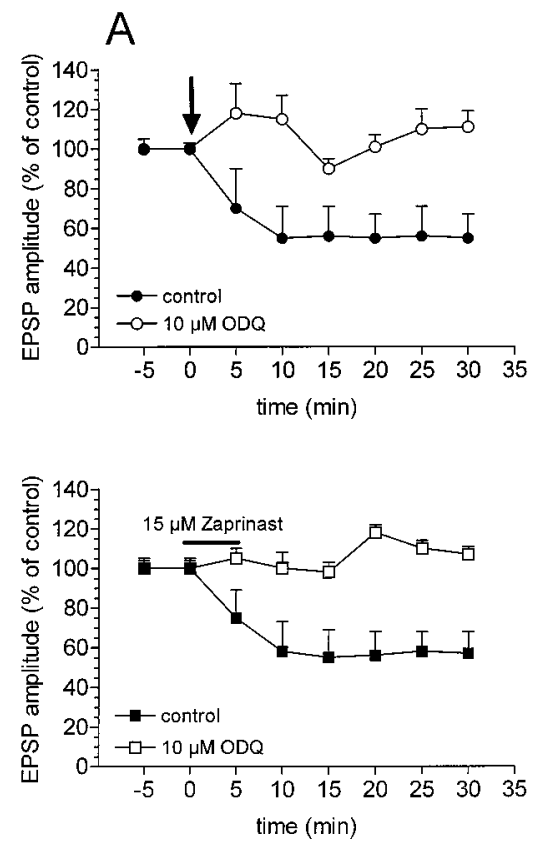

A
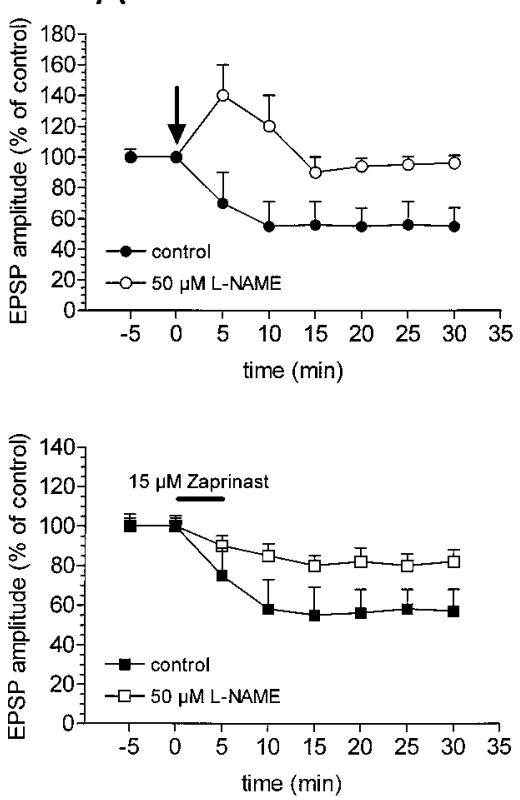

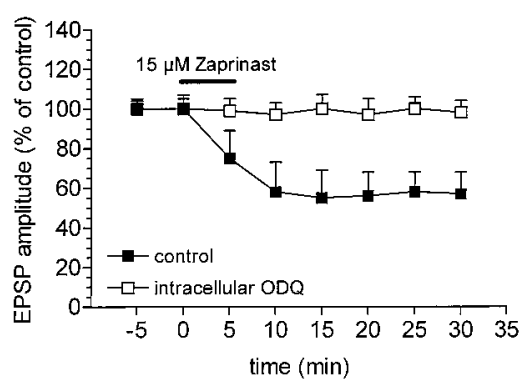

B
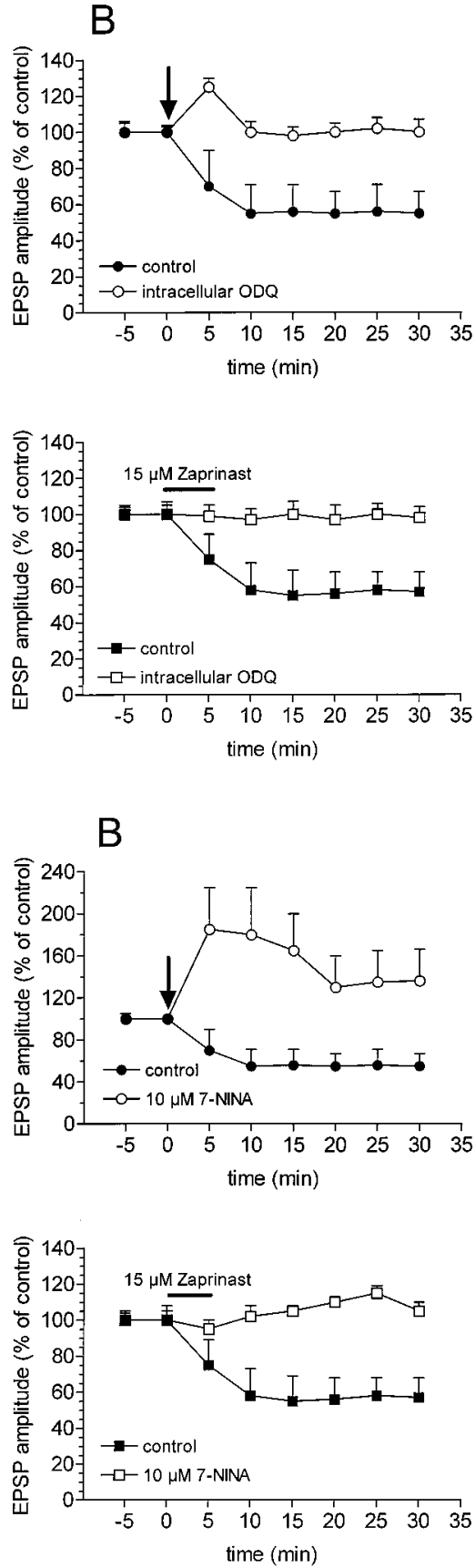

5) (Fig. 5B, top graph). Accordingly, the zaprinast-induced LTD also was suppressed under the same experimental conditions $(n=$ 5) (Fig. 5B, bottom graph).

Similar data were also obtained by using bath application of this inhibitor. In fact, $10 \mu \mathrm{M}$ ODQ blocked both the tetanusinduced LTD $(n=6)$ (Fig. $5 A$, top graph) and the zaprinastinduced LTD $(n=5)$ (Fig. $5 A$, bottom graph). Conversely, this dose of bath-applied ODQ failed to affect the LTD induced by intracellular application of cGMP $(n=3)$ (data not shown). Also under these experimental conditions there were no detectable changes in resting membrane potential or activity evoked by intracellular current injection (data not shown).

\section{Effect of L-NAME and 7-NINA}

NO is the best known activator of sGC (Wang and Robinson, 1997). Thus, we assumed that the blockade of the striatal NO production would interfere with the formation of corticostriatal LTD. In a first set of experiments $(n=6)$ we used L-NAME, an inhibitor of both nNOS and eNOS. Incubation of the slices (10 min) in the presence of $50 \mu \mathrm{M} \mathrm{L-NAME}$ prevented the formation of both the HFS- and zaprinast-induced LTD (Fig. 6A, top and bottom graph, respectively). Similar results were obtained by using 7-NINA $(n=6)$, a more selective inhibitor of nNOS (Moore and Handy, 1997); incubation of the slices in $10 \mu \mathrm{M}$ 7-NINA blocked both forms of LTD and unmasked a significant but transient post-tetanic potentiation (Fig. 6B). We also tested whether L-NAME could block EPSP depression induced by $5 \mu \mathrm{M}$ intracellular cGMP: in four of four experiments, we found that preincubation with $50 \mu \mathrm{M}$ L-NAME did not significantly alter the time course of LTD induced by this PKG activator (data not shown). Moreover, we examined the possibility that L-NAME 
A

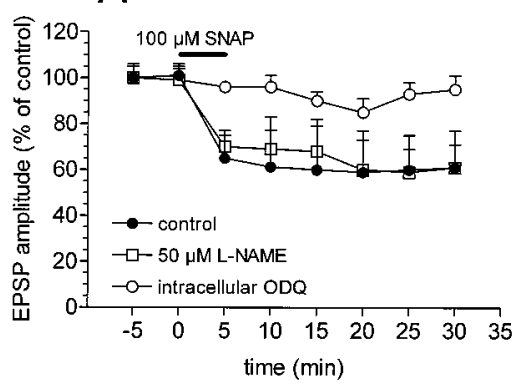

B

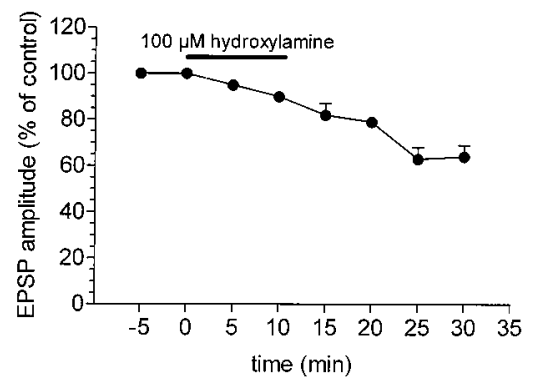

C
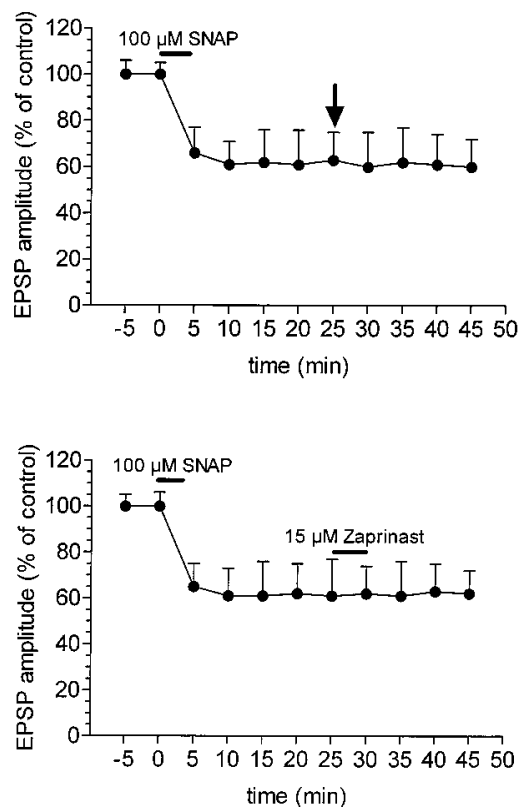

Figure 7. NO donors induce striatal LTD. $A$ Bath application of $100 \mu \mathrm{M}$ SNAP induces a fast and long-term decrease of EPSP amplitude (๑). This form of LTD is antagonized by $100 \mu \mathrm{M}$ intracellular ODQ $(\bigcirc)$ but not by bath application of $50 \mu \mathrm{M}$ L-NAME $(\square)$. $B$, Bath application of $100 \mu \mathrm{M}$ hydroxylamine also induces a persistent decrease of EPSP amplitude. Note, however, that this inhibitory action has a slower time course than that observed with SNAP. $C$, LTD induced by bath application of SNAP occludes HFS-induced (top graph) or zaprinast-induced LTD (bottom graph). could restore the original EPSP amplitude after the induction of LTD by HFS $(n=3)$ or zaprinast $(n=3)$; in none of these experiments was bath application of $50 \mu \mathrm{M}$ L-NAME able to reverse LTD (data not shown). In all of these experimental conditions there were no detectable changes in resting membrane potential or activity evoked by intracellular current injection (data not shown).

\section{Effect of SNAP and hydroxylamine}

To further confirm the role of NO in the induction of corticostriatal LTD, we investigated whether NO donors could mimic the LTD observed after HFS, PDE inhibition, or PKG activation. As shown in Figure $7 A$, bath application of $100 \mu \mathrm{M}$ SNAP for $5 \mathrm{~min}$ depressed the EPSP amplitude; this depression persisted even when the SNAP-containing solution was washed out $(n=10)$. The SNAP-induced LTD was blocked by intracellular ODQ (100 $\mu \mathrm{M} ; n=5)$ but not by bath application of $50 \mu \mathrm{M} \mathrm{L-NAME}(n=$ 4) (Fig. 7A). Moreover, this form of LTD occluded both HFSinduced $(n=5)$ (Fig. 7C, top graph) and zaprinast-induced LTD $(n=5)$ (Fig. 7C, bottom graph). Also, $100 \mu \mathrm{M}$ hydroxylamine, another NO donor, after $10 \mathrm{~min}$ of bath application produced a slower but significant reduction of EPSP amplitude, which reached a plateau after 25-30 min from the onset of drug application $(n=4)($ Fig. $7 B)$. The different time courses of the two NO donors are probably attributable to their different mechanisms of NO generation: although SNAP spontaneously generates NO by hydrolysis in the perfusing solution, hydroxylamine must be converted to NO by catalase and other metalloproteins. Both compounds are reported to raise cGMP levels in rat cerebellar slices (Southam and Garthwaite, 1991). There were no detectable changes in resting membrane potential or activity evoked by intracellular current injection when SNAP or hydroxylamine was applied (data not shown).

\section{Effect of PKG inhibition}

A final proof for a critical role of the NO/cGMP pathway in the formation of corticostriatal LTD should be the demonstration that an inhibitor of postsynaptic PKG is able to disrupt this form of synaptic plasticity. To examine this issue, we injected intracel- lularly Rp-8-Br-cGMPS, a selective PKG inhibitor. The neurons impaled with $1 \mu \mathrm{M}$ Rp-8-Br-cGMPS-filled electrodes were held for at least 15-20 min before the beginning of the LTD-induction protocols. As shown in Figure 8, the injection of this compound prevented the formation of HFS-induced (Fig. 8A) $(n=5)$, zaprinast-induced (Fig. $8 B)(n=5)$, and SNAP-induced (Fig. $8 C$ ) $(n=5)$ LTD. In three experiments the effects produced by Rp-8-Br-cGMPS were mimicked by the intracellular application ( $3 \mu \mathrm{M})$ of the membrane-impermeant PKG inhibitor Rp-cGMPS. Both Rp-8-Br-cGMPS and Rp-cGMPS did not cause any detectable change in resting membrane potential or activity evoked by intracellular current injection (data not shown).

\section{Cessation of test stimuli during zaprinast application}

The pharmacological data obtained by using zaprinast might suggest that there must be a basal NO tone sufficient to induce LTD when cGMP PDEs are inhibited or inactive, indicating that corticostriatal activation of NOS-positive interneurons may be unnecessary for the LTD induction. To test this hypothesis, we turned off the low-frequency corticostriatal test stimulation during the $5 \mathrm{~min}$ of application of $15 \mu \mathrm{M}$ zaprinast. Similar to the findings obtained in the cerebellum (Hartell, 1996), cessation of test stimuli during the application of this compound and for 10 min after its washout resulted in a significant inhibition of LTD induction $(n=6 ; p<0.01)$ (Fig. $8 D)$.

\section{Morphological analysis}

At the light microscopy level, DAB reaction product allowed the clear visualization of NOS immunoreactive neuronal bodies, dendrites, and nerve fiber network arborizing in the striatal neuropil and avoiding the white matter fascicles (Fig. 9A). At the electron microscopy level, NOS-positive axon terminals made symmetric synaptic contacts (identified by the presence of vesicle clustering at the presynaptic site, and a slight postsynaptic membrane density) with their targets; 152 of 200 labeled terminals formed synaptic contacts with unlabeled dendritic shafts, 44 of 200 labeled terminals formed contacts with unlabeled dendritic spine necks, and only 4 of 200 terminals formed contacts with unlabeled neuronal bodies. It is noteworthy that $\sim 50 \%$ of all NOS-positive 
Figure 8. The role of PKG activity in various forms of striatal LTD and the dependence on corticostriatal stimulation of zaprinast-induced LTD. A, HFSinduced LTD observed in control condition $(\bullet)$ is blocked by intracellular injection of $1 \mu \mathrm{M} \mathrm{Rp}-8-\mathrm{Br}-$ cGMPS, a PKG inhibitor (O). B, Zaprinast-induced LTD observed in control condition ( $\square$ ) is blocked by intracellular injection of $1 \mu \mathrm{M} \mathrm{Rp-8-Br-cGMPS}$, a PKG inhibitor ( $\square$ ). $C$, SNAP-induced LTD observed in control condition ( ) is blocked by intracellular injection of $1 \mu \mathrm{M} \mathrm{Rp-8-Br-cGMPS,} \mathrm{a} \mathrm{PKG}$ inhibitor $(\diamond)$. $D$, The effects of $15 \mu \mathrm{M}$ zaprinast application in the presence $(\boldsymbol{\Delta})$ and absence $(\triangle)$ of corticostriatal test stimulation are compared. When corticostriatal test stimulation $(0.1 \mathrm{~Hz})$ was interrupted during zaprinast application (5-6 min) and for a further period of $10 \mathrm{~min}$ after the washout, zaprinast-induced LTD was significantly inhibited $(n=6 ; p<0.01)$.
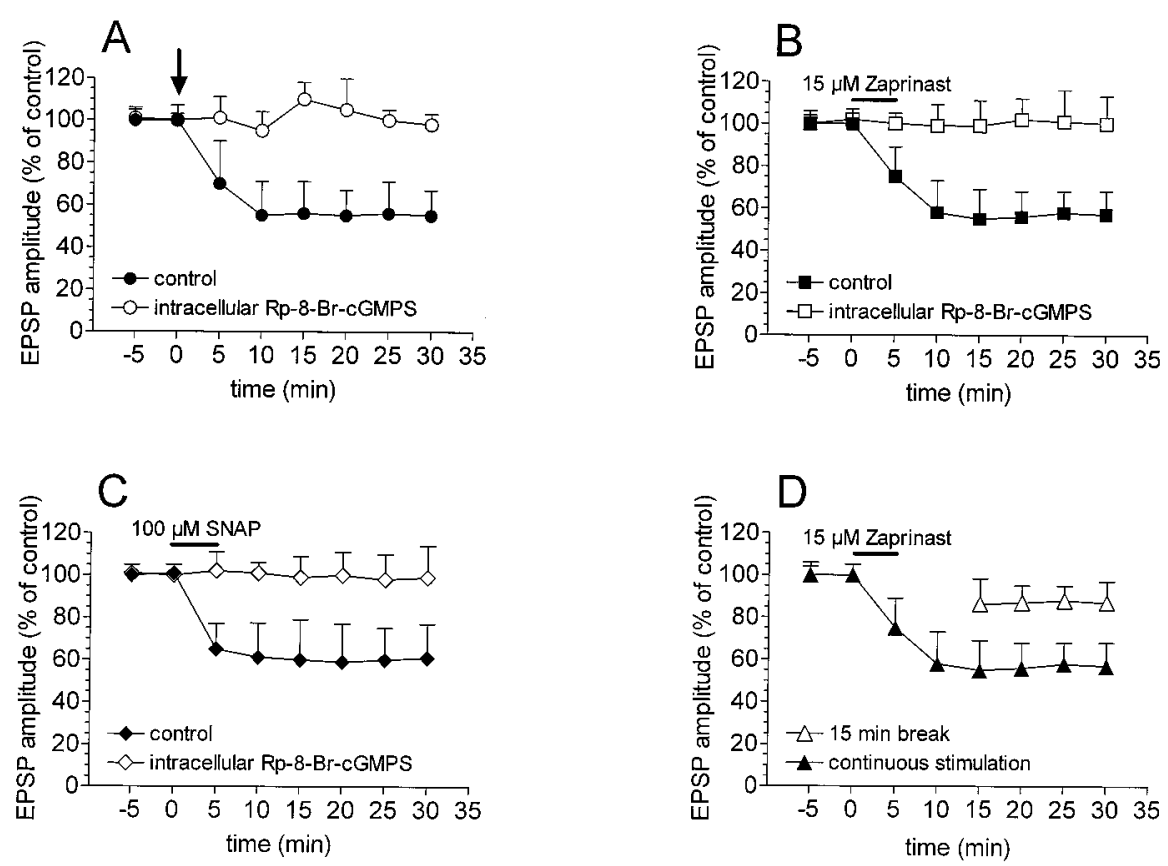

terminals observed to make synaptic contacts with unlabeled dendrites and spines were also contiguous to unlabeled presynaptic buttons, which in turn made synapses on common or nearby targets (Fig. 9B).

\section{DISCUSSION}

The present study represents the first evidence for a role of the $\mathrm{NO} / \mathrm{cGMP}$ pathway in the long-term regulation of the synaptic activity within the striatum. It has been shown that the induction of striatal LTD involves several other receptor-mediated and second messenger-related mechanisms: (1) membrane depolarization and action potential discharge of the spiny neuron during the conditioning high-frequency stimulation (Calabresi et al., 1992a,b; Lovinger et al., 1993; Choi and Lovinger, 1997), (2) activation of metabotropic but not of NMDA glutamate receptors (Calabresi et al., 1992b; Lovinger et al., 1993), (3) activation of dopamine receptors (Calabresi et al., 1992b, 1997c; Choi and Lovinger, 1997), and (4) increase of the intracellular $\mathrm{Ca}^{2+}$ concentration, which leads to $\mathrm{Ca}^{2+}$-dependent protein kinase activation (Calabresi et al., 1994, 1996a; Choi and Lovinger, 1997). Moreover, striatal LTD can be blocked by chronic lithium treatment (Calabresi et al., 1993), a procedure that is presumed to alter the phosphoinositide cycle (Berridge, 1993). The demonstration that the NO/cGMP pathway is required for the formation of corticostriatal LTD supports the idea that NO plays a critical role in the brain synaptic plasticity and provides an additional cellular substrate for learning abnormalities caused by NOS inhibitors (Hölscher, 1997). This demonstration is also important for two other reasons. First, this form of synaptic plasticity may represent a cellular substrate for motor learning involving basal ganglia. In fact, it has been proposed that long-term changes of synaptic activity at corticostriatal synapses may also be implicated in the pathogenesis of movement disorders such as Parkinson's disease and Huntington's disease (Calabresi et al., 1996b). Second, in the striatum the source of NO is well established (Boegman and Parent, 1988; Kawaguchi et al., 1995; FigueredoCardenas et al., 1997; Morello et al., 1997). In fact, striatal NOS immunoreactivity is selectively expressed in a group of interneu- rons whose function is regulated by the release of excitatory amino acids from the corticostriatal terminals. We have also shown here that axon terminals arising from this intrinsic NOSpositive neuronal network contact dendritic spines of putative projection neurons. Because these spiny neurons constitute the neuronal subtype expressing LTD after HFS of corticostriatal afferents, we can assume that the release of NO from interneurons represents a critical feed-forward mechanism required for the formation of LTD in spiny cells (Boegman and Parent, 1988; Kawaguchi et al., 1995; Figueredo-Cardenas et al., 1997; Morello et al., 1997).

Zaprinast, an inhibitor of cGMP PDEs, mimicked the tetanusinduced LTD. Because the intracellular cGMP concentration is dependent on the degradative activity of PDEs, this finding supports the involvement of cGMP in corticostriatal LTD. The zaprinast- and tetanus-induced synaptic depression were mutually occlusive, indicating that these two forms of synaptic plasticity share second messenger mechanisms. Because zaprinast is membrane permeant, it is possible that even when intracellularly applied this compound may diffuse outside the recorded neuron, targeting other sites of action. However, the finding that the effect of zaprinast could be mimicked by intracellular application of cGMP, which directly activates PKG and is membrane impermeant, makes this hypothesis unlikely and suggests a postsynaptic site of action.

Both forms of striatal LTD were not associated with significant changes in paired-pulse facilitation, suggesting that not only the induction phase, but also the maintenance phase of LTD requires postsynaptic mechanisms. Interestingly, it has recently been reported that in slices obtained from young rats, corticostriatal LTD is associated with increased paired-pulse facilitation (Choi and Lovinger, 1997). This observation, taken together with our findings, may indicate that the mechanisms underlying this form of synaptic plasticity in the striatum are developmentally regulated. In the hippocampus, zaprinast transiently reduces synaptic transmission through a mechanism that involves presynaptic adenosine A1 receptors but is triggered by the elevation of cGMP (Broome 

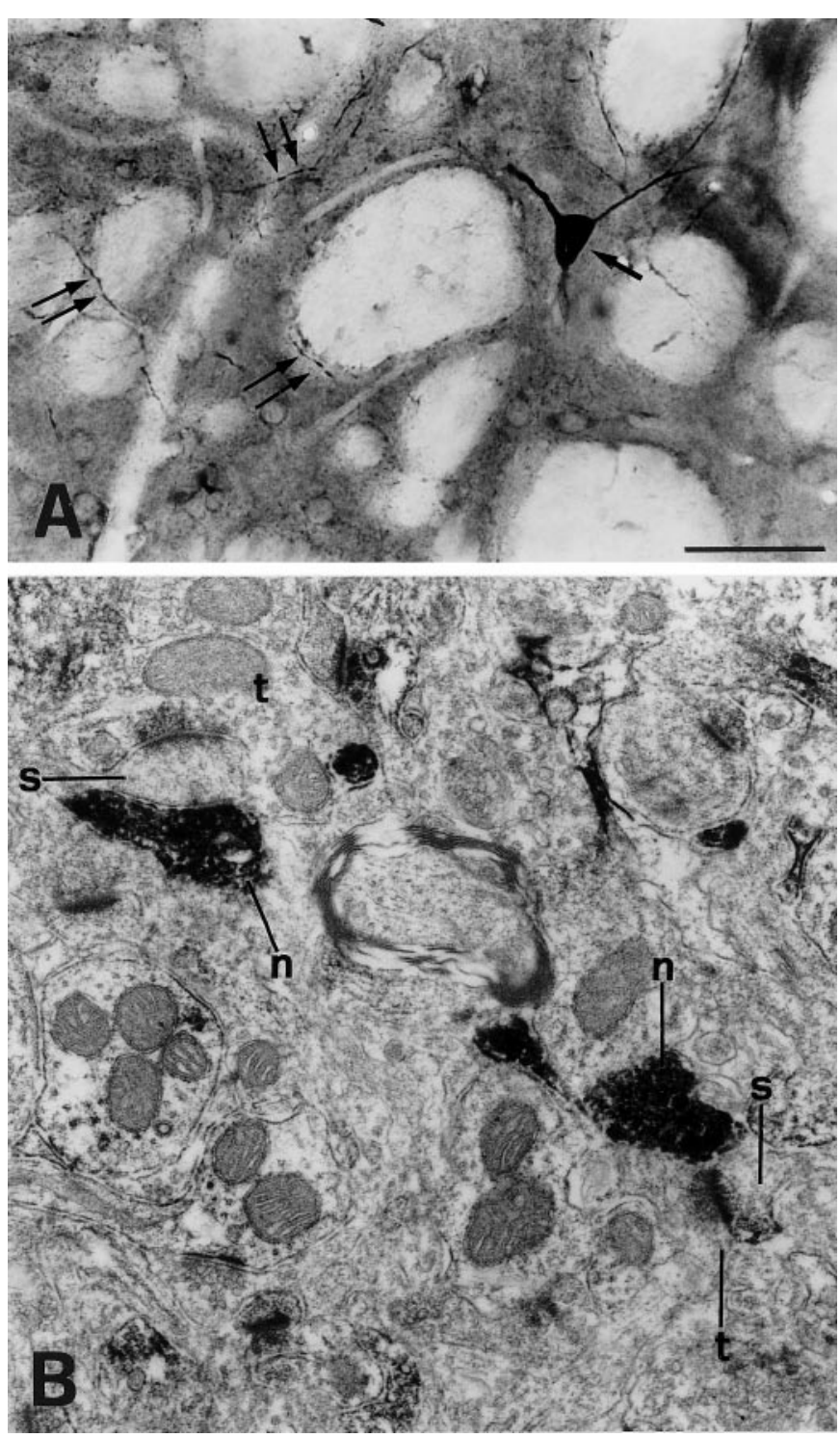

Figure 9. Light $(A)$ and electron $(B)$ photomicrographs of NOSimmunoreactive neurons labeled with $\mathrm{DAB}$ reaction product in the rat striatum. $A$, A multipolar NOS-positive neuron (arrow) is densely stained in the cell body and in its thick long dendrites; also a network of thin and thick neurites (double arrows) extends in the striatal neuropil. Large unstained areas represent white matter fascicles passing through the striatum. $B$, Two NOS-positive terminals $(n)$, each forming a symmetric synaptic contact with an unlabeled spine $(s)$. Note that each of the two NOS-positive terminals contacting the spine is also contiguous to an unlabeled terminal $(t)$, which in turn makes an asymmetric synaptic contact with the same target spine. Scale bar (shown in $A$ ): $A, 100 \mu \mathrm{m} ; B$, $0.7 \mu \mathrm{m}$.

et al., 1994). In the striatum, blockade of adenosine A1 receptors increased the baseline EPSP, indicating a tonic level of the adenosine receptor activation (Calabresi et al., 1997a; this study), but it did not prevent the zaprinast-induced depression of EPSPs, showing that the adenosine receptor is not involved in this form of synaptic plasticity.

The activity of PDEs regulates both the steady-state level and the turnover of intracellular cyclic nucleotides. For most excitable tissues, changes in the intracellular $\mathrm{Ca}^{2+}$ concentration also provide an important signal for cellular control, often interacting with cyclic nucleotides (Berridge, 1993). Biochemical studies have identified three neuronal PDE1 isoforms codified from three different genes having different properties: PDE1A, PDE1B, and PDE1C (Beavo, 1995; Z hao et al., 1997). These CaM-dependent PDEs can be inhibited by zaprinast at micromolar concentrations (Loughney et al., 1996). Interestingly, the striatum contains 3- to 17-fold higher levels of one isoform (PDE1B) of the CaMdependent PDEs than other brain areas (Polli and Kincaid, 1994; Yan et al., 1994). Immunocytochemistry confirmed that the PDE1B immunoreactivity is ubiquitous in the striatum (Polli and Kincaid, 1994). We found that the large majority of the striatal cGMP PDE activity that is inhibited by zaprinast is CaM dependent, suggesting that these PDEs, whose inhibition causes corticostriatal LTD, belong to this subfamily. Further evidence in favor of an involvement of PDE1 in the effect of zaprinast is the finding that both 8-MM-IBMX (Beavo, 1995; Yu et al., 1997) and KS-505a (Ichimura et al., 1996) mimicked the zaprinast-induced LTD in striatal spiny neurons. In fact, these two compounds have been reported to act at PDE1 more selectively than zaprinast, which also binds PDE5. The transient potentiation observed by using higher concentrations of 8-MM-IBMX (100 $\mu \mathrm{M})$ might be attributed to a site of action other than PDE1B. In fact, a lower dose $(20 \mu \mathrm{M})$ of this inhibitor only induced a long-lasting depression of the EPSP amplitude, mimicking the action of zaprinast and KS-505a.

The buffering of $\mathrm{Ca}^{2+}$ by intracellular BAPTA application blocks both HFS-induced (Calabresi et al., 1994) and zaprinastinduced LTD (this work), suggesting that elevations in intracellular $\mathrm{Ca}^{2+}$ are necessary for the induction of these forms of synaptic plasticity. However, these $\mathrm{Ca}^{2+}$ elevations should stimulate PDE1B rather than inhibit it. Activation of PDE1B should then decrease cytosolic levels of cGMP and diminish PKG activity. All of these observations seem to reveal a contradiction. However, there is a possible explanation for this apparent discrepancy. Brain PDEs are also regulated by phosphorylation and dephosphorylation processes; these reactions are operated by CaM-dependent protein kinase II and CaM-stimulated phosphatase (Wu et al., 1992). It is possible that the lowering of intracellular $\mathrm{Ca}^{2+}$ levels by BAPTA produces multiple biochemical effects on PDE activity, CaM-dependent kinases, and phosphatases. This chain of events might lead to complex and apparently contradictory results.

The intracellular concentration of cGMP is not only regulated by the degradative activity of the PDEs but also by its synthesis, which is controlled by the sGC. Interestingly, the distribution of sGC in the brain is similar to that of PDE1B1, and the expression of the sGC mRNA is prominent in the striatum (Matsuoka et al., 1992). This sGC is responsible for neurotransmitter-induced cGMP elevations in neurons. We found that the bath application of ODQ, a selective inhibitor of sGC (Garthwaite et al., 1995; Boxall and Garthwaite, 1996), abolished both zaprinast- and HFS-induced LTD. This inhibitory action was also observed when ODQ was injected into the postsynaptic neuron, suggesting that it is mediated by the inhibition of sGC localized in spiny cells. This interpretation is consistent with immunocytochemical and in situ hybridization studies, indicating a strong expression of $\mathrm{sGC}$ in spiny neurons (Ariano et al., 1982; Ariano, 1983; Furuyama et al., 1993).

Cortical stimulation releases glutamate both on spiny neurons and on NOS-positive striatal interneurons. In NOS-containing interneurons, glutamate increases intracellular $\mathrm{Ca}^{2+}$ and causes $\mathrm{NO}$ production. Because NO is freely diffusible, it can influence cGMP levels in spiny neurons via the activation of sGC present in 
these cells. Accordingly, LTD induced by HFS of cortical terminals, as well as the zaprinast-induced LTD, are blocked either by L-NAME, a nonselective NOS inhibitor, or by 7-NINA, a relatively more selective inhibitor of nNOS, suggesting that nNOS activity is responsible for this form of synaptic plasticity. Moreover, the finding that NOS inhibitors cannot reverse LTD once established seems to indicate that the NO/cGMP pathway is necessary for the induction of LTD but not for its maintenance. A further demonstration of a critical role of NO in the generation of corticostriatal LTD is represented by the experiments showing that NO donors are able to mimic LTD induced by either HFS or zaprinast. Accordingly, we found that SNAP-induced LTD occludes both of these forms of synaptic plasticity. In addition, we have demonstrated that postsynaptic inhibition of PKG blocks not only HFS- and zaprinast-induced LTD, but also SNAP-induced depression. Thus, we can conclude that these forms of synaptic plasticity require a common postsynaptic transduction mechanism, which is represented by the activation of PKG.

Finally, we have also shown that low-frequency cortical stimulation is essential for the induction of LTD by zaprinast. In fact, the cessation of the test stimuli prevented the induction of this form of synaptic plasticity. This latter experiment supports the notion that NOS-containing interneurons, activated by corticostriatal glutamatergic fibers, are a critical component of a feedforward circuit controlling LTD.

\section{REFERENCES}

Ariano MA (1983) Distribution of components of the guanosine $3^{\prime}-5^{\prime}-$ phosphate system in rat caudate-putamen. Neuroscience 10:707-723.

Ariano MA, Lewicki JA, Brandwein HJ, Murad F (1982) Immunohistochemical localization of guanylate cyclase within neurons of rat brain. Proc Natl Acad Sci USA 79:1316-1320.

Beavo JA (1995) Cyclic nucleotide phosphodiesterases: functional implications of multiple isoforms. Physiol Rev 75:725-748.

Beavo JA, Reifsnyder DH (1990) Primary sequence of cyclic nucleotide phosphodiesterase isozyme and the design of selective inhibitors. Trends Pharmacol Sci 11:150-155.

Berridge MJ (1993) A tale of two messengers. Nature 365:388-389.

Bliss TVP, Collingridge GL (1993) A synaptic model of memory: longterm potentiation in the hippocampus. Nature 361:31-39.

Boegman RJ, Parent A (1988) Differential sensitivity of neuropeptide Y, somatostatin and NADPH-diaphorase containing neurons in rat cortex and striatum to quinolinic acid. Brain Res 445:358-362.

Bon C, Böhme GA, Doble A, Stutzmann J-M, Blanchard J-C (1992) A role for nitric oxide in long-term potentiation. Eur $\mathrm{J}$ Neurosci 4:420-424.

Boulton CL, Southam E, Garthwaite J (1995) Nitric oxide-dependent long-term potentiation is blocked by a specific inhibitor of soluble guanylyl cyclase. Neuroscience 3:699-703.

Boxall RA, Garthwaite J (1996) Long-term depression in rat cerebellum requires both NO synthase and NO-sensitive guanylyl cyclase. Eur J Neurosci 8:2209-2212.

Broome MR, Collingridge GL, Irving AJ (1994) Activation of the NOcGMP signalling pathway depresses hippocampal synaptic transmission through an adenosine receptor-dependent mechanism. Neuropharmacology 33:1511-1513.

Calabresi P, Mercuri NB, Bernardi G (1990) Synaptic and intrinsic control of membrane excitability of neostriatal neurons. II. An in vitro analysis. J Neurophysiol 63:663-675.

Calabresi P, Mercuri NB, De Murtas M, Bernardi G (1991) Involvement of GABA systems in the feed-back regulation of glutamate- and GABA-mediated synaptic potentials in the striatum. J Physiol (Lond) 440:581-599.

Calabresi P, Maj R, Mercuri NB, Bernardi G (1992a) Coactivation of D1 and D2 dopamine receptors is required for long-term synaptic depression in the striatum. Neurosci Lett 142:95-99.
Calabresi P, Maj R, Pisani A, Mercuri NB, Bernardi G (1992b) Longterm synaptic depression in the striatum: physiological and pharmacological characterization. J Neurosci 12:4224-4233.

Calabresi P, Pisani A, Mercuri NB, Bernardi G (1993) Lithium treatment blocks long-term synaptic depression in the striatum. Neuron 10:955-962.

Calabresi P, Pisani A, Mercuri NB, Bernardi G (1994) Post-receptor mechanisms underlying striatal long-term depression. J Neurosci 14:4871-4881.

Calabresi P, Pisani A, Centonze D, Bernardi G (1996a) Role of Ca ${ }^{2+}$ in striatal LTD and LTP. Semin Neurosci 8:321-328.

Calabresi P, Pisani A, Mercuri NB, Bernardi G (1996b) The corticostriatal projection: from synaptic plasticity to basal ganglia disorders. Trends Neurosci 19:19-24.

Calabresi P, Centonze D, Pisani A, Bernardi G (1997a) Endogenous adenosine mediates the presynaptic inhibition induced by aglycemia at corticostriatal synapses. J Neurosci 17:4509-4516.

Calabresi P, De Murtas M, Bernardi G (1997b) The neostriatum beyond the motor function. Neuroscience 78:39-60.

Calabresi P, Saiardi A, Pisani A, Baik J-H, Centonze D, Mercuri NB, Bernardi G (1997c) Abnormal synaptic plasticity in the striatum of mice lacking dopamine D2 receptors. J Neurosci 17:4536-4544.

Cherubini E, Herrling PL, Lanfumey L, Stanzione P (1988) Excitatory amino-acids in synaptic excitation of rat striatal neurons in vitro. J Physiol (Lond) 400:677-690.

Choi S, Lovinger DM (1997) Decreased probability of neurotransmitter release underlies striatal long-term depression and postnatal development of corticostriatal synapses. Proc Natl Acad Sci USA 94:2665-2670.

Crépel F, Jaillard D (1990) Protein kinases, nitric oxide and long-term depression of synapses in the cerebellum. NeuroReport 1:133-136.

Daniel H, Hemart N, Jaillard D, Crepel F (1993) Long-term depression requires nitric oxide and guanosine $3^{\prime}, 5^{\prime}$ cyclic monophosphate production in rat cerebellar Purkinje cells. Eur J Neurosci 5:1079-1082.

East SJ, Parry-Jones A, Brotchie JM (1996) Ionotropic glutamate receptors and nitric oxide synthesis in the rat striatum. NeuroReport 8:71-75.

Figueredo-Cardenas G, Morello M, Sancesario G, Bernardi G, Reiner A (1997) Colocalization of somatostatin, neuropeptide Y, neuronal nitric oxide synthase and NADPH-diaphorase in striatal interneurons in rats. Brain Res 735:317-324.

Furuyama T, Inagaki S, Takagi H (1993) Localizations of $\alpha-1$ and $\beta-1$ subunits of soluble guanylate cyclase in the rat brain. Mol Brain Res 20:335-344.

Garthwaite J, Southam E, Boulton CL, Neilsen EB, Schmidt K, Mayer B (1995) Potent and selective inhibition of nitric oxide-sensitive guanylyl cyclase by $1 \mathrm{H}-[1,2,4]$ oxadiazolo[4,3-a]quinoxalyn-1-one. Mol Pharmacol 48:184-188.

Glaum SR, Slater NT, Rossi DJ, Miller RJ (1992) Role of metabotropic glutamate (ACPD) receptors at the parallel fibre-Purkinje cell synapse. J Neurophysiol 68:1453-1462.

Graybiel AM (1990) Neurotransmitters and neuromodulators in the basal ganglia. Trends Neurosci 13:244-254.

Graybiel AM (1995) Building action repertoires: memory and learning functions of the basal ganglia. Curr Opin Neurobiol 5:733-741.

Gribkoff VK, Lum-Ragan JT (1992) Evidence for nitric oxide synthase inhibitor-sensitive and insensitive hippocampal synaptic potentiation. J Neurophysiol 68:639-642.

Groves PM (1983) A theory of the functional organization of the neostriatum and the neostriatal control of voluntary movement. Brain Res Rev 5:109-132.

Haley JE, Malen PL, Chapman PF (1993) Nitric oxide inhibitors block long-term potentiation induced by weak but not strong tetanic stimulation at physiological brain temperatures in rat hippocampal slices. Neurosci Lett 160:85-88.

Hartell NA (1996) Inhibition of cGMP breakdown promotes the induction of cerebellar long-term depression. J Neurosci 16:2881-2890.

Herrling PL (1985) Pharmacology of the corticocaudate excitatory postsynaptic potential in the cat: evidence for its mediation by quisqualate or kainate receptors. Neuroscience 14:417-426.

Hölscher C (1997) Nitric oxide, the enigmatic neuronal messenger: its role in synaptic plasticity. Trends Neurosci 7:298-303.

Horikawa H, Armstrong WE (1988) A versatile means of intracellular labelling: injection of biocytin and its detection with avidin conjugates. J Neurosci Methods 25:1-11.

Ichimura M, Eiki R, Osawa K, Nakanishi S, Kase H (1996) KS-505a, an 
isoform-selective inhibitor of calmodulin-dependent cyclic nucleotide phosphodiesterase. Biochem J 316:311-316.

Jiang ZG, North RA (1991) Membrane properties and synaptic responses of rat striatal neurones in vitro. J Physiol (Lond) 443:533-553.

Kato K, Zorumski CF (1993) Nitric oxide inhibitors facilitate the induction of hippocampal long-term potentiation by modulating NMDA responses. J Neurophysiol 70:1260-1263.

Kawaguchi Y, Wilson CJ, Augood SJ, Emson PC (1995) Striatal interneurones: chemical, physiological and morphological characterization. Trends Neurosci 18:527-535.

Kitai ST, Kocsis JD, Preston RJ, Sugimori M (1976) Monosynaptic inputs to caudate neurons identified by intracellular injection of horseradish peroxidase. Brain Res 109:601-606.

Kleschevnikov AM, Sokolov MV, Kuhnt U, Dawe GS, Stephenson JD, Voronin LL (1997) Changes in paired-pulse facilitation correlate with induction of long-term potentiation in area CA1 of rat hippocampal slices. Neuroscience 76:829-843.

Lev-Ram V, Makings LR, Keitz PF, Kao JPY, Tsien RY (1995) Longterm depression in cerebellar Purkinje neurons results from coincidence of nitric oxide and depolarization-induced $\mathrm{Ca}^{2+}$ transients. Neuron 15:407-415.

Lev-Ram V, Jiang T, Wood J, Lawrence DS, Tsien RY (1997) Synergies and coincidence requirements between NO, cGMP, and $\mathrm{Ca}^{2+}$ in the induction of cerebellar long-term depression. Neuron 18:1025-1038.

Linden DJ, Connor JA (1992) Long-term depression of glutamate currents in cultured cerebellar Purkinje neurons does not require nitric oxide signaling. Eur J Neurosci 4:10-15.

Loughney K, Martins TJ, Harris EAS, Sadhu K, Hicks JB, Sonnenburg WK, Beavo JA, Ferguson K (1996) Isolation and characterization of cDNAs corresponding to two human calcium, calmodulin-regulated, 3',5'-cyclic nucleotide phosphodiesterases. J Biol Chem 271:796-806.

Lovinger DM, Tyler EC, Merritt A (1993) Short- and long-term synaptic depression in rat neostriatum. J Neurophysiol 70:1937-1949.

Malen PL, Chapman PF (1997) Nitric oxide facilitates long-term potentiation, but not long-term depression. J Neurosci 17:2645-2651.

Matsuoka I, Giuili G, Poyard M, Stengel D, Parma J, Guellaen G, Hanoune J (1992) Localization of adenylyl and guanylyl cyclase in rat brain by in situ hybridization: comparison with calmodulin mRNA distribution. J Neurosci 12:3350-3360.

Moore PK, Handy RLC (1997) Selective inhibitors of neuronal nitric oxide synthase: is no NOS really good NOS for the nervous system? Trends Pharmacol Sci 18:204-211.

Morello M, Reiner A, Sancesario G, Karle EJ, Bernardi G (1997) Ultrastructural study of nitric oxide synthase-containing striatal neurons and their relationship with parvalbumin-containing neurons in rats. Brain Res 776:30-39.
Polli JW, Kincaid RL (1994) Expression of a calmodulin-dependent phosphodiesterase isoform (PDE1B1) correlates with brain regions having extensive dopaminergic innervation. J Neurosci 14:1251-1261.

Schuman EM, Madison DV (1991) A requirement for the intercellular messenger nitric oxide in long-term potentiation. Science 254:1503-1506.

Shibuki K, Okada D (1991) Endogenous nitric oxide release required for long-term synaptic depression in the cerebellum. Nature 349:326-328.

Smith AD, Bolam JP (1990) The neuronal network of the basal ganglia as revealed by the study of synaptic connections of identified neurons. Trends Neurosci 13:259-265.

Son H, Hawkins RD, Martin K, Kiebler M, Huang PL, Fishman MC, Kandel ER (1996) Long-term potentiation is reduced in mice that are doubly mutant in endothelial and neuronal nitric oxide synthase. Cell 87:1015-1023.

Southam E, Garthwaite J (1991) Comparative effects of some nitric oxide donors on cyclic GMP levels in rat cerebellar slices. Neurosci Lett 130:107-111.

Thompson WJ, Appleman MM (1971) Multiple cyclic nucleotide phosphodiesterase activities from rat brain. Biochemistry 10:311-316.

Vincent SR, Kimura H (1992) Histochemical mapping of nitric oxide synthase in the rat brain. Neuroscience 46:755-784.

Walsh JP (1993) Depression of excitatory synaptic input in rat striatal neurons. Brain Res 608:123-128.

Wang X, Robinson PJ (1997) Cyclic GMP-dependent protein kinase and cellular signaling in the nervous system. J Neurochem 68:443-456.

Williams JH, Li Y-G, Nayak A, Errington ML, Murphy KPSJ, Bliss TVP (1993) The suppression of long-term potentiation in rat hippocampus by inhibitors of nitric oxide synthase is temperature and age dependent. Neuron 11:877-884.

Wu Z, Sharma RK, Wang JH (1992) Catalytic and regulatory properties of calmodulin-stimulated phosphodiesterase isozymes. In: Advances in second messenger and phosphoprotein research (Strada SJ, Hidaka H, eds), pp 29-43. New York: Raven.

Yan C, Bentley JK, Sonnenburg WK, Beavo JA (1994) Differential expression of the $61 \mathrm{kDa}$ and $63 \mathrm{kDa}$ calmodulin-dependent phosphodiesterases in the mouse brain. J Neurosci 14:973-984.

Yu J, Wolda SL, Frazier AL, Florio VA, Martins TJ, Snyder PB, Harris EA, McCaw KN, Farrell CA, Steiner B, Bentley JK, Beavo JA, Ferguson K, Gelinas R (1997) Identification and characterisation of a human calmodulin-stimulated phosphodiesterase PDE1B1. Cell Signal 9:519-529.

Zhao AZ, Yan C, Sonnenburg WK, Beavo JA (1997) Recent advances in the study of $\mathrm{Ca}^{2+} / \mathrm{CaM}$-activated phosphodiesterases. In: Advances in second messenger and phosphoprotein research, Vol 31 (Corbin JD, Francis SH, eds), pp 237-251. Philadelphia: Lippincott-Raven. 